\title{
Effect of tephra depth on vegetation development in areas affected by volcanism
}

\author{
Mariela Gómez-Romero • Roberto Lindig-Cisneros • \\ Sebastiana Galindo-Vallejo
}

Published online: 28 February 2007

(C) Springer Science + Business Media B.V. 2007

\section{Erratum to: Plant Ecol \\ DOI 10.1007/s11258-005-9017-z}

This erratum is published as wrong table \& figure legends were published earlier. The re-corrected legends should be now read as:

Table 2 Total area, number of vegetation patches, and canopy cover of all vegetation patches in relation with tephra depth class in the "Mesa de Cutzato" 1.44 ha study plot

Fig. 3 Relationships between tephra depth (as mean depth for each depth class) and the density of vegetation patches in "a" (calculated as the number of patches per hectare $)\left(R^{2}=0.67\right.$, $\left.F_{(1,6)}=12.08, P=0.013\right)$ and with vegetation patch area per hectare in "b"

Fig. 5 Relationships between depth of the tephra layer and plant height and depth of the tephra layer and biomass (as dry weight), for Lupinus elegans plants growing on fine grained tephra (a) and coarse grained tephra (b) under greenhouse conditions. Two plants growing directly on the growing medium (treatment 1) were damaged by an un-identified herbivore and therefore excluded from the regression analysis (indicated by triangles in graph a)

The online version of the original article can be found at http://dx.doi.org/10.1007/s11258-005-9017-z

M. Gómez-Romero · R. Lindig-Cisneros ·

S. Galindo-Vallejo

Laboratorio de Ecología de Restauración, Facultad

de Biología, Universidad Michoacana de San Nicolás

de Hidalgo, Ciudad Universitaria, Morelia,

Michoacán, México

R. Lindig-Cisneros ( $\square)$

Apartado Postal 18, Administración 3, Santa Maria,

Morelia C.P. 58091 Michoacán, México

e-mail: lindig@zeus.umich.mx 